\title{
دراسة تحليلية للنمو في الأسعار المحلية والعالمية لأهم المحاصيل في التجارة الخارجية الزراعية المصرية
}

رجب مغاوري علي زين، يسرا السعودي عبد المقصود شقرة، إيمان السيد قاسم البهجي قسم الاقتصاد الزراعي وإدارة الأعمال الزراعية- كلية الزراعة-جامعة المنوفية

Received: Oct. 8, 2019

Accepted: Oct. 27, 2019

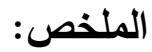

تتسم الأسعار والسياسات السعرية بأهية كبيرة نظرا لدورها في توجيه الموارد بين مختلف أنواع الإنتاج وكنلك في

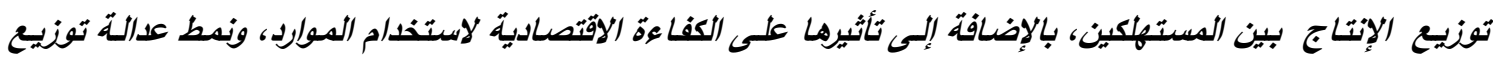

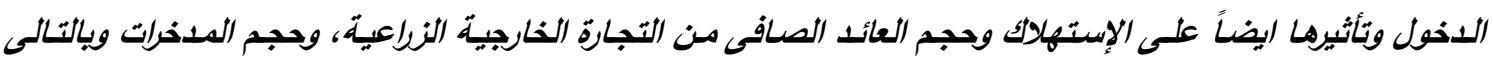

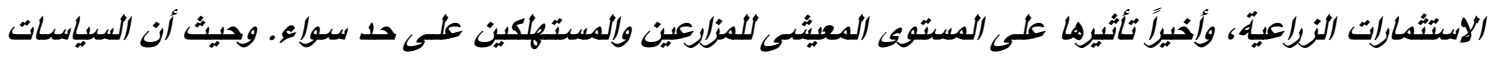

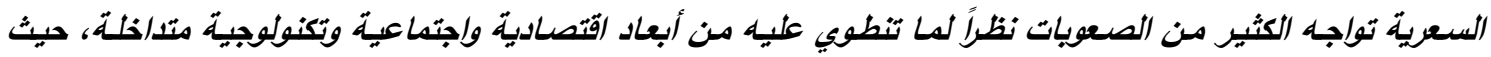

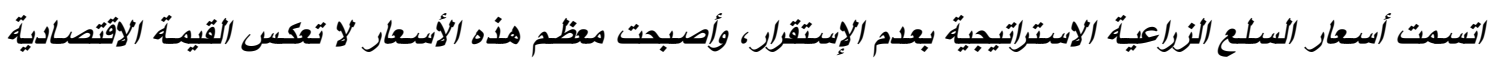

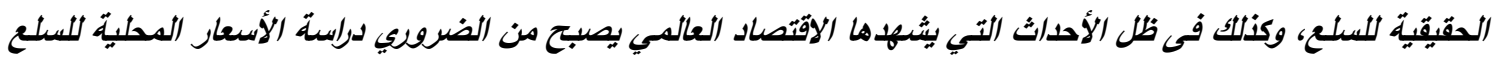
الاسترتيجية واتجا هها ومدى إنحرافها عن نظيرتها العالمية. الكلمـات المفتاحية: الأسعار المطلية وإلعالمية- السياسـات السعرية- المحاصيل الاستراتيجية فحى الزراعة المصريةالأسعار النقدية وإلحقيقية.

استخدام الموارد، وتواجه السياسات السعرية الكثير من

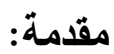
الصـعويات نظراً لمسا تنطوي عليـه مـن أبعـاد اقتصـادية تثير مختلف الاراسات الى الأهمية الكبيرة للأسعار

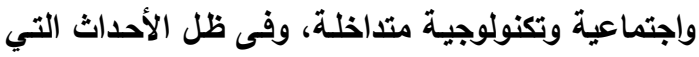
والسياسات السعرية نظرا لدورها في توجيه الموارد بين يشـهـها الاقتصـاد العـالمي حاليـاً يصبح من الضـروري إعادة النظر الى أسعار الحاصلات الزراعية الاسترتيجية

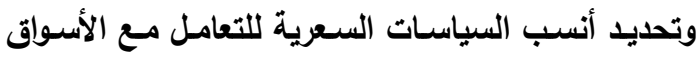

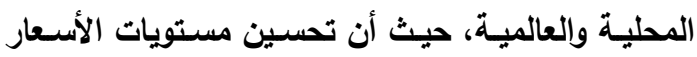
المزرعية بهدف تثجيع المزارعين على إنتاج المحاصيل الزراعية بصفة عامـة والاستراتيجية منها بصفة خاصـة الكزية الهدف الرئيسي للسياسات السعرية الزراعية. هذا وتؤثر

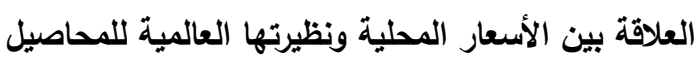

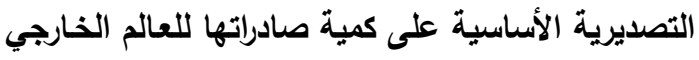

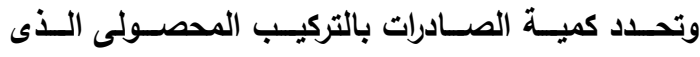

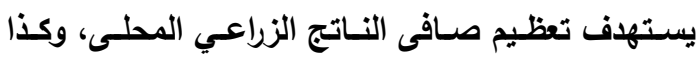

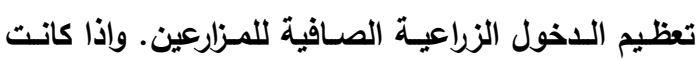
مختلف أنواع الإنتاج وكذلك في توزيع الإنتاج بين

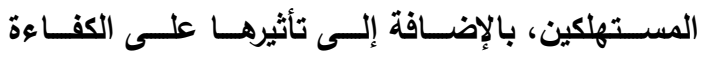
الاقتصادية لاستخدام الموارد، ونمط عدالة توزيع الدخول

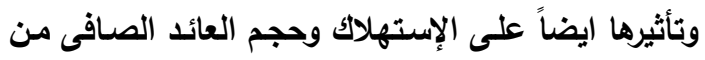

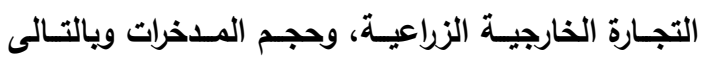

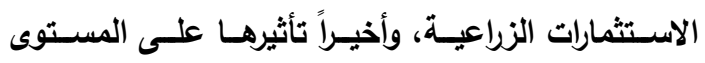

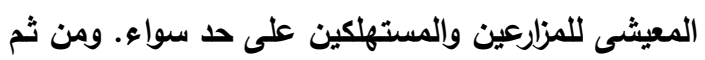

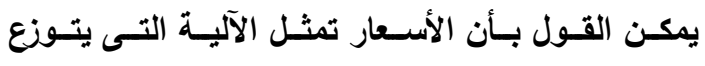

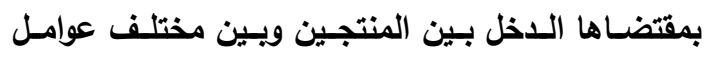
الإنتاج، إضافة إلى أنها أداه هامة تسـاعد متخذى القرار

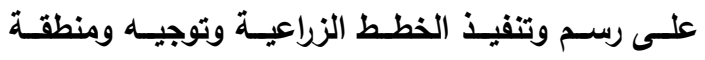


4. محاولة الوصول إلى توصيات تفيد واضعي السياسة الزراعية في رسم سياسة لتسعير الحاصلات الزراعية موضع الاراسة، ويما يتفق مع الأهداف العامة للسياسة الزراعية خاصة والسياسة الاقتصادية المصرية عامة، ويما يتفق مع اهداف الدولة للتنمية.

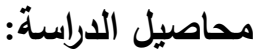

تم تحديد محاصيل الاراسة وفقاً لأهميتها النسبية في التجارة الخارجية الزراعية المصرية وكذلك لأهميتها في

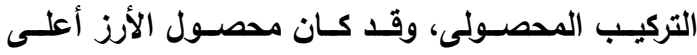

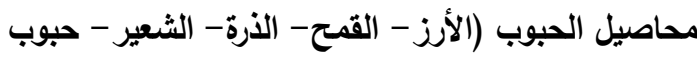

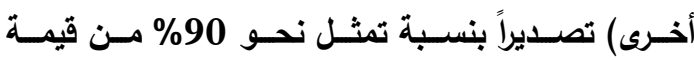
صادراتها، في حين يمثل نحو 52\% من قيمة صادرات الحبوب ومشتقاتها 1، كما يمثل نحو 20\% من إجمالي مساحة المحاصيل الصيفية خلال الثُلاث سنوات الأخيرة (2014-206)، في حين مثل محصول القطن نحو 90 مسن قيمـة صـادرات محاصـيل الأليـاف (القطن الكتـان - الجـوت)، ممـا يعكس أهميـة محصـولي الأرز والقطن كمحاصيل تصديرية في التجارة الخارجية الزراعية

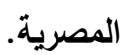

وحيث تمثل محاصيل الحبوب (القمح- الأرز - الذرة-

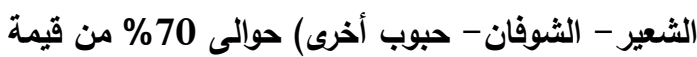
واردات المحاصيل الحقليـة، وتبين أن محصبولي القــح

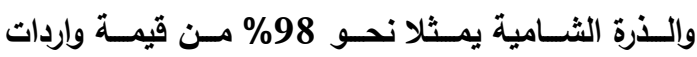
الحبوب، كما يثغل محصول القمح حوالى نصف مساحة

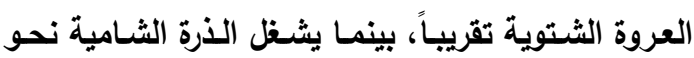
26 مــن جملــة المســاحة الصــيفية خـلال الفتـرة

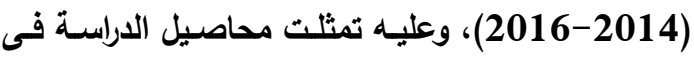

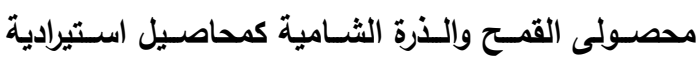
ومحصـولى الأرز الأبسيض والقطـن الثـسر كمحاصـيل

تصديرية هامة.

1 مشتقات صادرات الحبوب تشمل دقيق قمح، دقيق شليم، دقيق ذرة، سميد وجريش، شوفان، مساحيق منتجات، شعير ناشظ، نشاء جلوتين فئن
السياســة الســرية الزراعيـة وراء عـزوف المـزارع عـن زراعة المحاصيل الاستراتيجية وما قد يترتب على ذلك من عنداعن

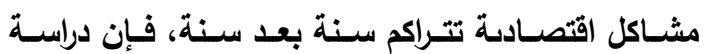

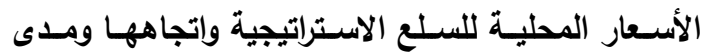

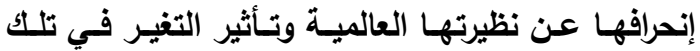
العلاقات السعرية على الاقتصاد القومى المصرى يعتبر

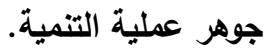

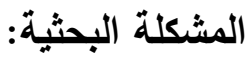
التسـت أسـعار الســـع الزراعيـة الاستراتيجية بعدام

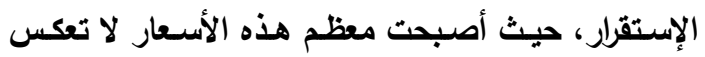
القيمة الاقتصادية الحقيقية للسلع، بالإضافة إلى إختلال التوازن بين أسعار المنتجات الزراعية ويعضها وإختلال

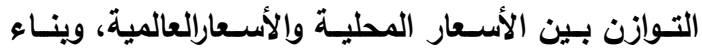

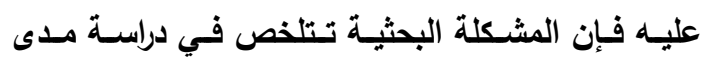
استقرار الأسعار المحلية للمحاصيل الزراعية الاستراتيجية التي يحصل عليها المزارع ومدى مواكبتها مـع التغيرات في الأسعار التصديرية والاستيرادية، وتأثير ذلك بدوره

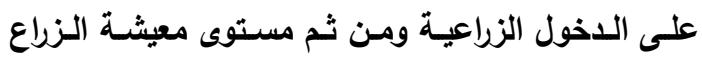
المنتجين لهذه المحاصيل.

$$
\text { الهدف البحثى: }
$$

يستهـف البحث إلقـاء الضـوء علـى مـدى مواكبـة

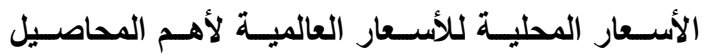

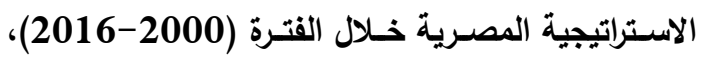
وفى سبيل تحقيق هذا الهلف الرئيسي تم تناول مجموعة من الأهداف الفرعية والتي يمكن توضيحها في الآتي: 1. الاستعراض التاريخي للسياسات السعرية الزراعية للمحاصيل موضع الاراسة في مصر. 2. دراسة الاتجاه الزمنى العام للأسعار المحلية والعالمية

النقدية والحقيقية وتقدير معدلات النمو لكل منهما. 3. مقارنة الأسعار المحلية والأسعار العالمية لمحاصيل الاراسة ومدى تثتتها وقربها من بعضها. 
ودرجـة النظافـة، وكانــت الكميـة الفائضــة لـــى الـزراع المرغوب تسليمها تورد بسعر أعلى، وكان يتم تحصيل غرامسات مسن الـزراع الــين لايـوردون الحصـة المقـررة

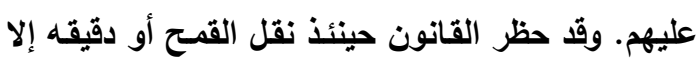
بتصـريح مـن وزارة التمـوين، وفـى عـام 1945 قـررت

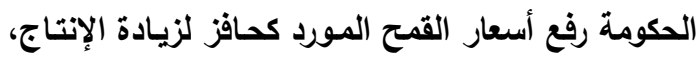

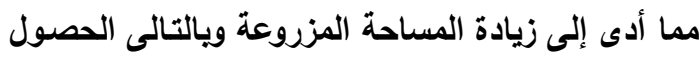

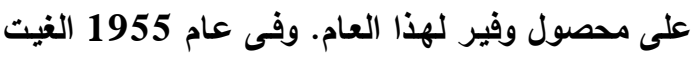
القيود على المساحة المزروعة كما خفض سعر الأردب من القـح تمشيا مـع انخفاض الأسـعار العالمية، إلا أن هذه القيود أعيدت مرة أخرى فى العام التالى. ويداية من التحن

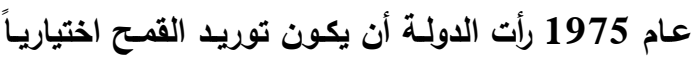
وقد استمر ذلك حتى عام 1983، ثم أصبح إجبارياً بعد ذلكك مرة أخرى، وقد تظلت الدولية منذ عام 1987 عن

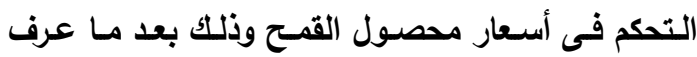
بسياسات التحرر الاقتصادى.

ب- السياسة السعرية للارة الثامية: خضع محصول الذرة منذ زمن بعيد لنظام التسويق ، نطيق الحر، نظراً لأان الكميات المستوردة من هذا المحصول لم تكن إلا بنسبة ضئيلة من الاستهلاك المحلى، حيث كان

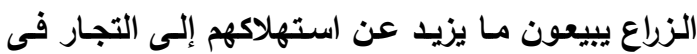

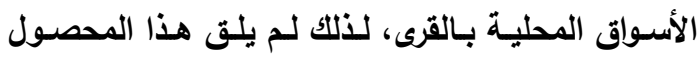

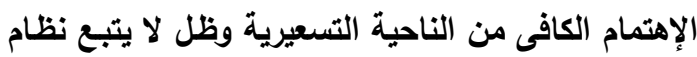
التوريد عن الحيازة، وظل هذا النظام سـارى حتى عام الامديه

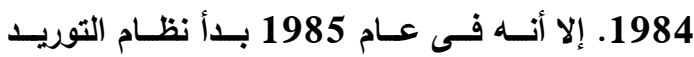
الإجبارى لمحصول الذرة الثامية، وكان نظام توريد جزئى

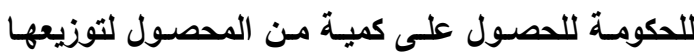
على مصانع الأعلاف أو توريده لهيئة السلع التموينية، وكان ذلك من أهم أسباب تناقص المساحة عام 1986،

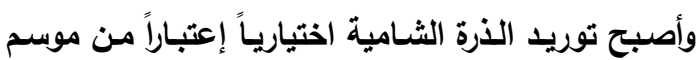
1986 والمواسم التالية، حيث عدلت الدولة عن تسويقه مع بداية مرحلة التحرر الاقتصادى. الطريقة البحثية ومصادر البيانات: اعتمد البحث لتحقيق أهدافه على أسـاليب التحليل الاقتصادى الوصفي والكمي، حيث استخدت المتوسطات الحسابية بالإضافة إلى استخدام أسلوب تحليل الاتحدار لتقدير معادلات الاتجاه الزمني للتعرف على شكل واتجاه أسـعار محاصيل الاراسـة المحليـة والعالميـة النقليـة والحقيقية، هذا واعتمد البحث على البيانات الثانوية التي تصدر من قبل الجهات المعنية والمتمثلة في النشرات الاقتصادية التي يصدرها قطاع الثئون الاقتصادية بوزارة الزراعة واستصلاح الأراضي، والجهاز المركزي للتعبئة

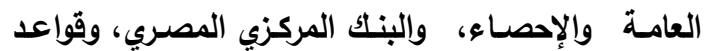

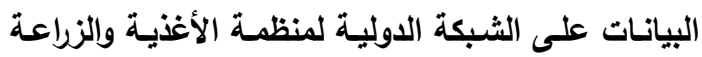
(الفاو)، والبنك الدولي.

أولاً: السياسة السعرية الزراعية المصرية: تمثل السياسة السعرية جملة المبادئ والإجراءات والأسس التي يتم في ضوئها تخطيط وتحديد الأسعار أو التأثير عليها بما يؤمن تحقيق الأهداف الاقتصادية فئسية والاجتماعية. والسياسة السعرية ليست غاية بحد ذاتها وإنما هي وسيلة لإقامة نظام سعري سليم، وعليه فان السياسة السعرية بمفهومها الواسع تمثل كل الوسيائل المباشرة وغير المباشرة للتأثير على هيكل الأسعار

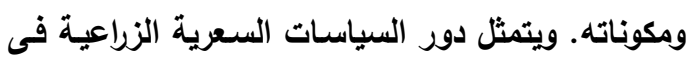
معالجة الفروق بين الأسعار المحلية والأسعار العالمية من ناحية، ويين تكاليف الإنتاج وأسعار البيع من ناحية أخرى، ومن منطلق تلك الأهمية فقل استوجب الأمر تناول ملامح تلك السياسات للمحاصيل موضع الدراسة. أ- السياسة السعرية للقمح: فى أوائل الخمسينات ونظرا لعدم كفاية الناتج محليا من الحبوب تدخلت الدولة في سوق القمح، ويدأت فى ونى اصدار قرارات تفرض على الزراع تسليم حصة محددة من لدن محصول القمح إلى بنك التسليف الزراعى حينئذ، ويقوم البنك بسداد الثمن للمزارع حسب السعر المحدد للصنف التفول 
وإنهاء نظام التعامل الحر فى القطن الزهر، ومنذ عام

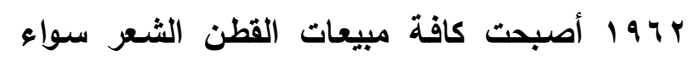
لأغراض التصدير أو الاستهلاك المحلي تتم من خلادل

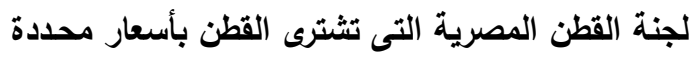

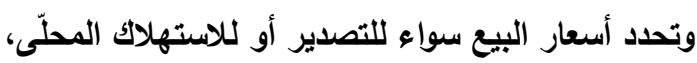

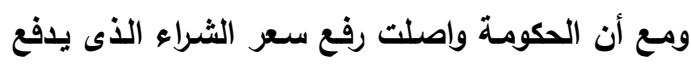

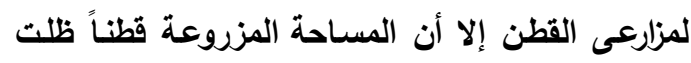

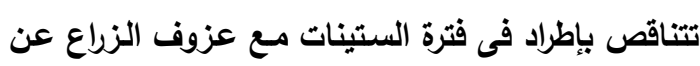

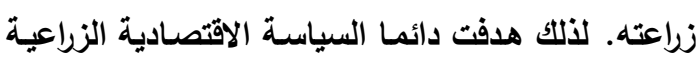
القطنية البحث عن الأسواق الخارجية التى يمكن فيها التعاقد على أكبر سعر ممكن لصادراتها من القطن طويل الفيل

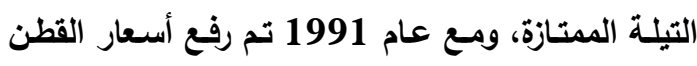
لتصل الى نحو ثلثى السعر العالمى.

ثثائاً: تطور الأسعار المحلية والعالمية لمحاصيل الدراسة: أ- القمح:

تعكس بيانـات الجدول (1) تطور الأسـعار المحليـة

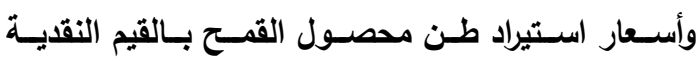

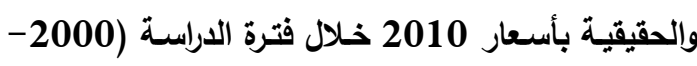

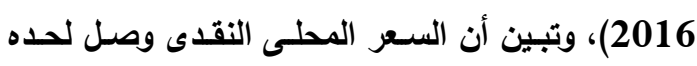
الأدنى عام 2003 والبالغ نحو 130 دولار ثم أخذ في الأني الارتفاع حتى وصل لحده الأقصى البالغ نحو 470 دولار

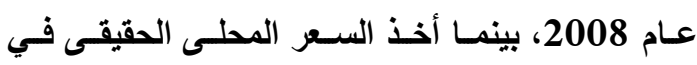
الانخفاض مـن حـ أقصى بلـغ نحو 380 دولار عـام

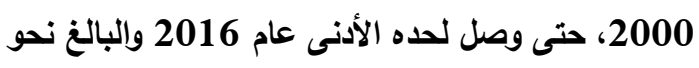

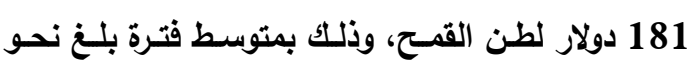

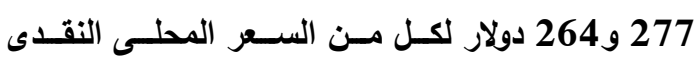

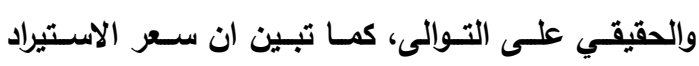

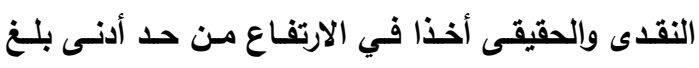
حـوالى 146 و158 دولار عــام 2000 حتـى وصـــلا

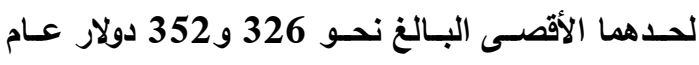
2011، ثم أخذ كل منهم في الانخفاض مرة أخرى، وذلك البك بمتوسط فترة بلغ حوالى 221 و247 فئ دولار لكل منهم

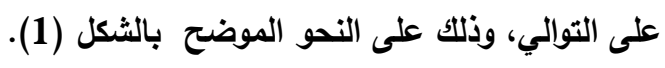

ج- السياسة السعرية للأرز: بدأ التدخل الحكومى فى عمليـات تداول الأرز منذ عـام 1939، حيث بـأت بتحديــ أسسعار جبريسة لـلأرز الأبيض فى ذلك العام، فى حين بدأت فى تحديد أسعار

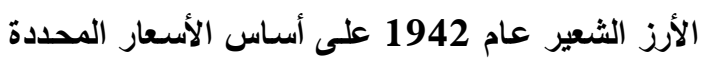

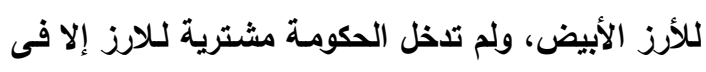

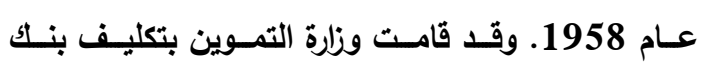

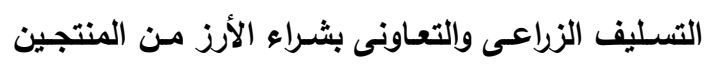
والتجار، ويدأ نظام التسويق بالجمعيات التعاونية للهيئة العامة للإصلاح الزراعى عام 1963، 1967، وعمم النظام عام

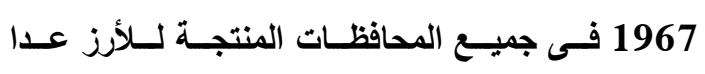
محافظتى الإسماعيلية والسويس والتى كان فيها التوريد

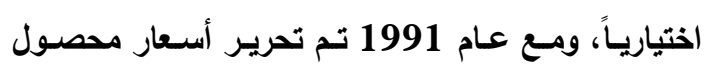
الأرز بالكامل. وقد اعتمدت الدولة على السياسة السعرية

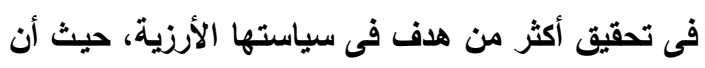

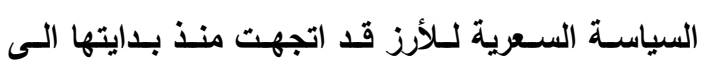

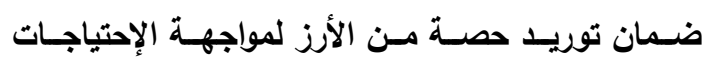

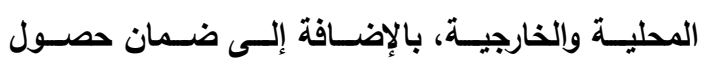

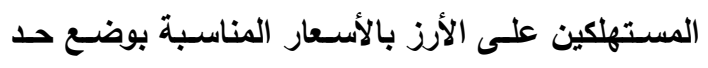

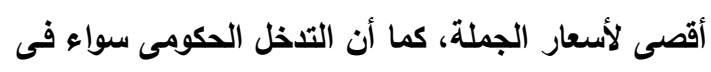

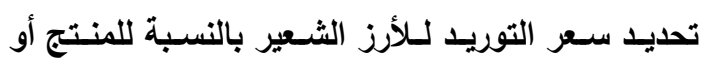

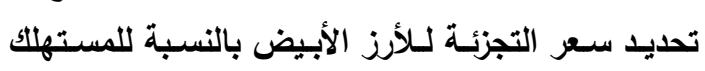

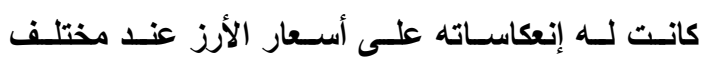
مستويات المسلك التسويقى للأرز فى مصر.

د - السياسة السعرية للقطن: مرت السياسة السعرية للقطن فى مصر بثلاثة

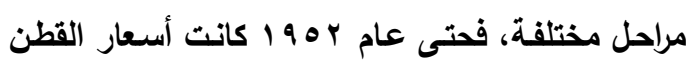

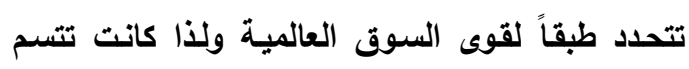

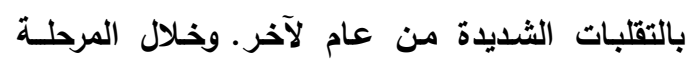

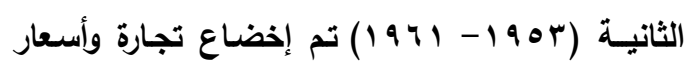
القطن الثعر لإثراف لجنة القطن المصرية، ولقد شهدت الثهات هذه الفترة تقلبات محدودة فى أسعار القطن. أما المرحلة الفرنة

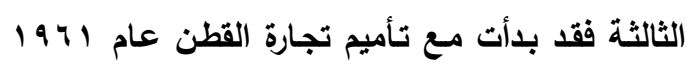


جدول (1): الأسعار المحلية وأسعار استيراد محصولى القمح والذرة الثامية بالقيم النقدية والحقيقية بأسعار عام 2010

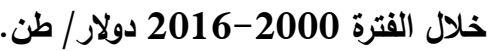

\begin{tabular}{|c|c|c|c|c|c|c|c|c|c|c|c|}
\hline \multirow[b]{2}{*}{ للالواردات } & \multirow{2}{*}{ 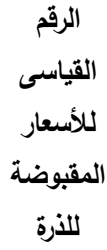 } & \multirow{2}{*}{ لللألسعارى } & \multicolumn{4}{|c|}{ الذرة الثشامية } & \multicolumn{4}{|c|}{ القمح } & \multirow[b]{2}{*}{ السنة } \\
\hline & & & الاستيرد & الحقيقى " السعى & الاستيراد & النقلى السعر & | الاستيرد & السقلى السقى" & الاستيراد & النقدى النقى & \\
\hline 92 & 31 & 53 & 124 & 572 & 115 & 175 & 158 & 380 & 146 & 200 & 2000 \\
\hline 89 & 31 & 53 & 129 & 501 & 115 & 154 & 169 & 332 & 151 & 176 & 2001 \\
\hline 77 & 32 & 54 & 162 & 442 & 125 & 140 & 189 & 293 & 146 & 160 & 2002 \\
\hline 78 & 35 & 58 & 168 & 342 & 130 & 118 & 192 & 225 & 149 & 130 & 2003 \\
\hline 78 & 52 & 76 & 193 & 321 & 150 & 167 & 214 & 213 & 167 & 161 & 2004 \\
\hline 79 & 52 & 85 & 173 & 345 & 137 & 179 & 206 & 228 & 163 & 194 & 2005 \\
\hline 74 & 54 & 85 & 195 & 348 & 145 & 188 & 230 & 230 & 171 & 197 & 2006 \\
\hline 78 & 80 & 88 & 261 & 353 & 205 & 281 & 334 & 234 & 262 & 205 & 2007 \\
\hline 86 & 71 & 194 & 303 & 367 & 260 & 260 & 344 & 243 & 296 & 470 & 2008 \\
\hline 100 & 70 & 122 & 175 & 361 & 175 & 251 & 241 & 238 & 241 & 291 & 2009 \\
\hline 100 & 100 & 100 & 206 & 334 & 206 & 334 & 245 & 323 & 245 & 323 & 2010 \\
\hline 93 & 94 & 129 & 334 & 349 & 309 & 326 & 352 & 306 & 326 & 395 & 2011 \\
\hline 98 & 115 & 139 & 331 & 311 & 323 & 359 & 331 & 300 & 323 & 416 & 2012 \\
\hline 96 & 119 & 142 & 357 & 273 & 344 & 325 & 274 & 264 & 264 & 377 & 2013 \\
\hline 99 & 120 & 151 & 224 & 266 & 222 & 321 & 286 & 256 & 283 & 388 & 2014 \\
\hline 102 & 122 & 152 & 182 & 287 & 186 & 350 & 222 & 236 & 227 & 359 & 2015 \\
\hline 95 & 131 & 153 & 197 & 188 & 187 & 245 & 206 & 181 & 195 & 277 & 2016 \\
\hline & & & 219 & 351 & 196 & 246 & 247 & 264 & 221 & 277 & المتوسط \\
\hline & & & 357 & 572 & 344 & 359 & 352 & 380 & 326 & 470 & الاعلى \\
\hline & & & 124 & 188 & 115 & 118 & 158 & 181 & 146 & 130 & الادنى \\
\hline
\end{tabular}

المصدر: جمعت وحسبت من قواعد البيانات الزراعية لمنظمة الأغذية والزراعة للأمم المتحدة (الفاو) على الثبكة الدولية للمعلومات

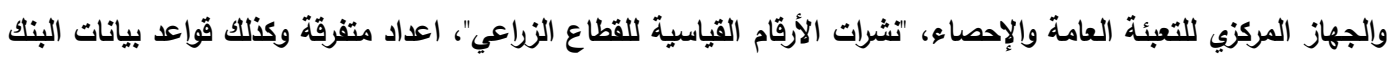


شكل(1): تطور الأسعار المحلية وأسعار استيراد طن محصول القمح بالقيم النقية والحقيقية بأسعار 2010 خلال القترة (2016-2000) بالدولار / طن : (200)

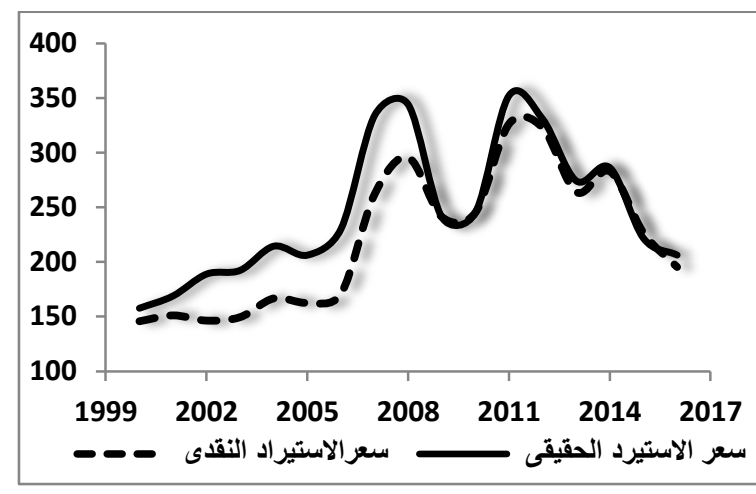

دولار فـى نهايـة الفترة بمتوسط بلـغ نحو 351 دولار، بينما أخذ كلا من سعر الاستيراد النقدى والحقيقيى لطن الذرة الثـامية في الارتفاع من حد أدنى بلغ نحو الاستئرد 115 و124 دولار عام 2000 حتى حد أقصى عام 2013

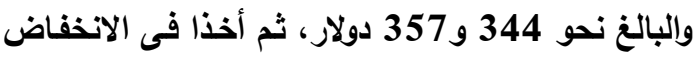

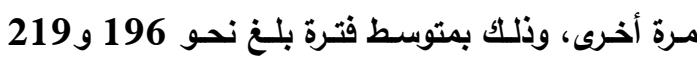

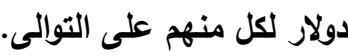

ويدراسة الاتجاه الزمنى العام لكل من السعر المحلى وسعر الاستيراد النقىى والحقيقي للطن من محصول الذرة الثامية خلال فترة الدراسة، تبين أن النموذج التكعيبي هو الأفضل للتعبير عن التطور الحادث في قيمة كل منهما، وذلك عند مستوى معنوية 1\% وعلى النحو الذى النى توضحه معادلات جدول رقم (2). وتعكس بيانات الجدول النمو السنوي لسعر الاستيراد

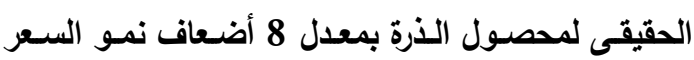
المحلى الحقيقى تقريباً، ويوضـح معامل التصديد المعدل

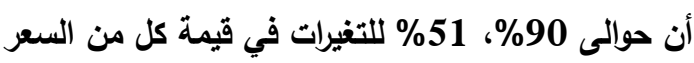
المحلى وسعر الاستيراد الحقيقى على التوالي ترجع إلى العوامل الاقتصادية والتكنولوجية المرتبطة بالزمن.

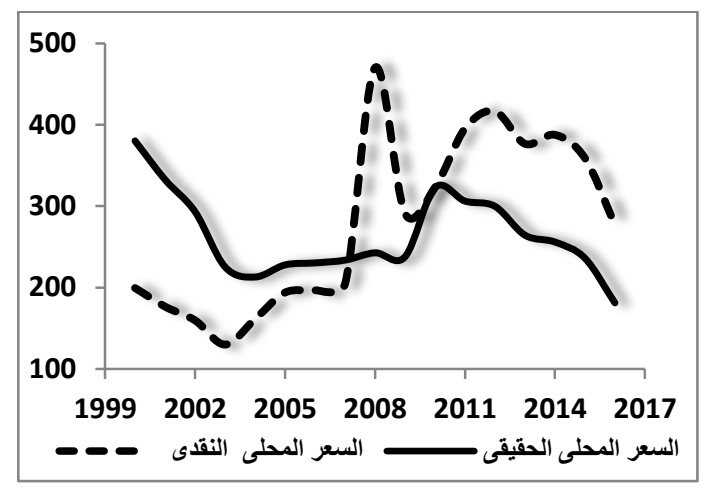

المصدر: بيانات جدول رقم (1).

ويدراسة الاتجاه الزمنى العام تبين أن النموذج التكعيبي هو الأفضل للتعبير عن التطور الحادث في كل لتهني من السعر المحلى النقدى والحقيقي وسعر الاستيراد النقاى لمحصول القمح، في حين كان النموذج التربيعي الأفضل ليعكس قيمة سعر استيراد طن محصول القمح الحقيقى، وذلك عند مستوى معنوية 1\% على النحو الأى توضحه معادلات جدول رقم (2). وتثثير بيانات الجدول أن معدل نمو السعر المحلى وسعر استيراد طن محصول القمح الحقيقي يقدر بنحو 6,1\% و 2,6\% لكل منهم على التوالي، ويوضح معامل التصديد المعدل لكل

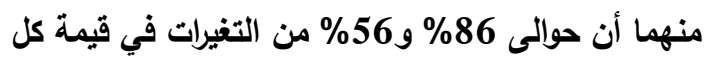
منهما على التوالي ترجع إلى العوامل الاقتصادية والتكنولوجية المرتبطة بالزمن.

$$
\text { ب - لذرة الشامية: }
$$

توضح بيانات الجدول (1) والثكل (2) إرتفاع السعر المحلى النقدى لطن محصول الذرة الثـامية مـن نحو 118 دولار عـام 2003 إلى حسالى 359 دولار كحد أقصى عام 2012 بمتوسط بلع نحو 246 دولار، بعكس

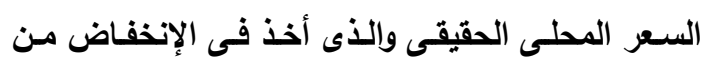
نحو 572 دولار كد أقصى عام 2000 إلى نحو 188 
R. M. A. Zein, et al.,

جدول (2): تطور السعر المحلى وسعر استيراد محصولى القمح والذرة الثامية النقدي والحقيقي بأسعار 2010 خلال الفترة (2000-2016) بالدولار/ طن.

\begin{tabular}{|c|c|c|c|c|}
\hline \multicolumn{2}{|r|}{ الذرة الشامية } & \multicolumn{2}{|r|}{ القمـح } & \multirow[b]{2}{*}{ البند } \\
\hline السنوى \% معل النمو & معادلة الاتجاه الزمني & السنوى \% معل النمو & معادلة الاتجاه الزمني & \\
\hline 12 & 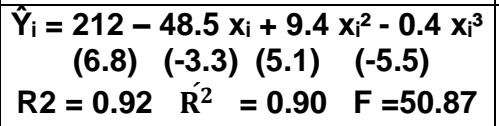 & 14 & 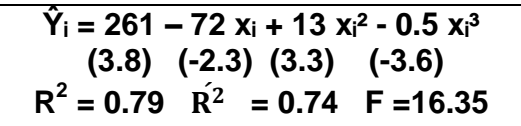 & السعر المحلى النقدى \\
\hline 13 & $\begin{array}{c}\hat{Y}_{i}=165-40 x_{i}+8.2 x_{i}{ }^{2}-0.3 x_{i}^{3} \\
(3.2) \quad(-1.7) \quad(2.7) \quad(-3.1) \\
R 2=0.74 \quad R^{2}=0.69 \quad F=12.6\end{array}$ & 10 & $\begin{array}{l}\hat{Y}_{i}=146-14 x_{i}+5.1 x_{i}{ }^{2}-0.2 x_{i}{ }^{3} \\
(2.3) \quad(-0.5) \quad(1.4) \quad(-1.8) \\
R 2=0.60 \quad R^{2}=0.51 \quad F=6.53\end{array}$ & سعر الاستيراد \\
\hline 0,9 & $\begin{aligned} & \hat{Y}_{i}=663-110 x_{i}+12 x_{i}{ }^{2}-0.4 x_{i}^{3} \\
&(18.9) \quad(-6.7) \quad(5.8)(-5.5) \\
& R 2=0.92 \quad R^{2}=0.90 \quad F=48.35\end{aligned}$ & 6 & $\begin{array}{c}\hat{Y}_{i}=483-104.8 x_{i}+12.9 x_{i}{ }^{2}-0.5 x_{i}^{3} \\
(20.67) \quad(-9.59)(9.29) \\
R^{2}=0.89 \quad R^{2}=0.86 \quad F=34.32\end{array}$ & السعر المحلى \\
\hline 8,4 & 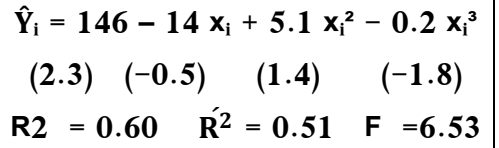 & 2,6 & $\begin{aligned} \hat{\mathbf{Y}}_{\mathrm{i}}=92.1+37.1 \mathrm{x}_{\mathrm{i}}-1.7 \mathrm{x}_{\mathrm{i}}^{2} \\
(2.7) \quad(4.25) \quad(-3.6) \\
\mathrm{R} 2=\mathbf{0 . 6 2} \quad \mathrm{R}^{2}=0.56 \quad \mathrm{~F}=11.37\end{aligned}$ & سعر الاستيراد \\
\hline
\end{tabular}

المصدر : جمعت وحسبت من بيانات جدول رقم (1).

شكل(2): تطور الأسعار المحلية وأسعار استيراد طن محصول الذرة الثامية بالقيم النقدية وإلحقيقية بأسعار 2010 خلال

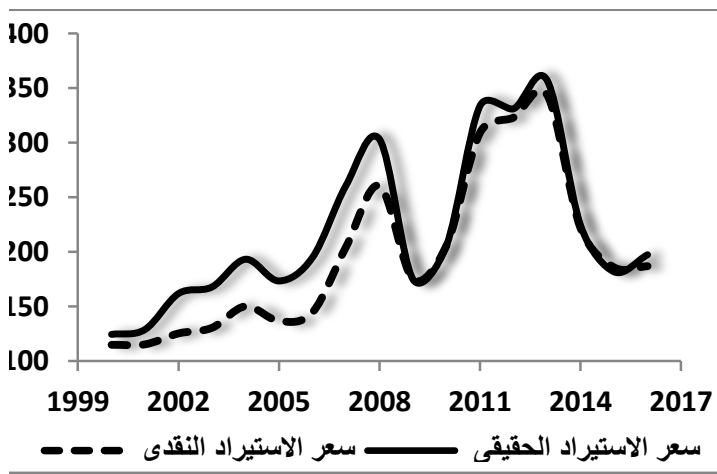

والأى أخذ في الإخفاض من نحو 240 نولار كد أقصى عام 2000 حتى حد أدنى بلغ نحو 85 دولار عام 2016، ونلك بمتوسط فترة بلغ حوالى 351 و470 دولار لكل منهم على بلى التوالى، بينما أخذ سعر تصلير الأرز الأبيض النقاى والحقيقى

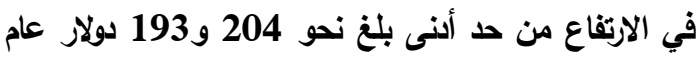
2001 حتى وصل لحده الأقصى عام 2009 والبالغ نحو 734 و748 دولار، ثم أخذ في الانخفاض مرة أخرى، ونلتك بمتوسط فترة بلغ نحو 428، 436 لكل منهم على التوالي،

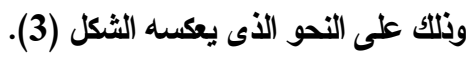

الفترة (2000-2016) بالدولار/طن.

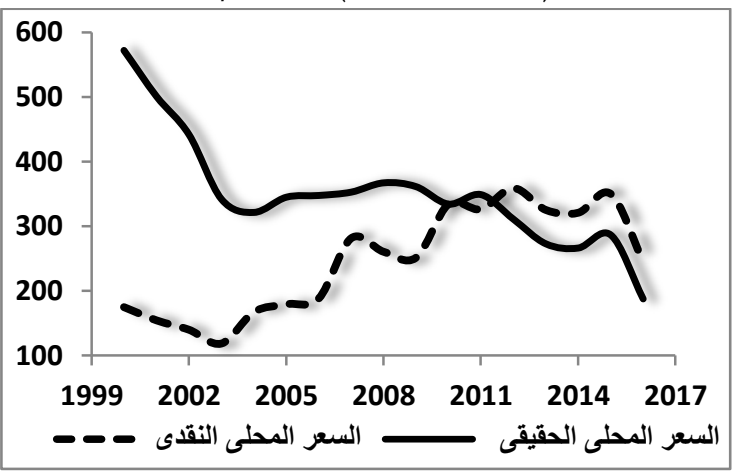

المصدر : بيانات جدول رقم (1)

ج- الأرز الأبيض:

توضح بيانات الجدول رقم (3) تطور الأسعار المحلية وأسعار تصلير طن محصول الأزز الأبيض بالقيم النقية والحقيقية بأسعار 2010 خلال فترة الدراسة (20002016)، حيث أخذ السعر المحلى النقىى في الارتفاع من حد

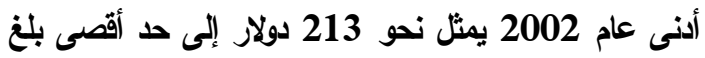
نحو 506 دولار عام 2011 لطن الأرز الأبيض والذى أخذ بعده في الانفاض مرة أخرى، بعكس السعر المحلى الحقيقي 
R. M. A. Zein, et al.,

جدول(3): الأسعار المحلية وأسعار تصدير محصولى الأرز الأبيض والقطن الثعر بالقيم النقدية والحقيقية خلال الفترة 2016-2000 دولار/ طن.

\begin{tabular}{|c|c|c|c|c|c|c|c|c|c|c|c|}
\hline \multirow{2}{*}{ 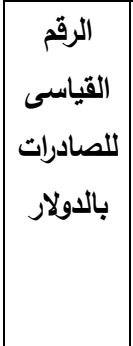 } & \multirow[b]{2}{*}{ 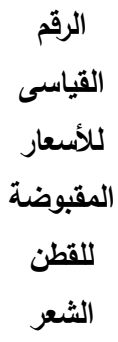 } & \multirow[b]{2}{*}{ 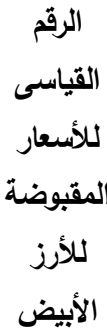 } & \multicolumn{4}{|c|}{ القطن الثعر } & \multicolumn{4}{|c|}{ الأرز الأبيض } & \multirow[b]{2}{*}{ البأسعار } \\
\hline & & & لكقيق & الحقيقى المقى & ر النقدى & النقدى المطى & التصدير & الحقيقى & التصدير & 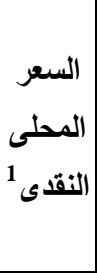 & \\
\hline 104 & 38 & 32 & 2017 & 4411 & 2092 & 1681 & 276 & 751 & 286 & 240 & 2000 \\
\hline 106 & 38 & 32 & 2152 & 4424 & 2279 & 1691 & 193 & 656 & 204 & 213 & 2001 \\
\hline 95 & 40 & 37 & 2165 & 3768 & 2046 & 1519 & 241 & 579 & 227 & 213 & 2002 \\
\hline 93 & 57 & 54 & 1993 & 2748 & 1859 & 1558 & 275 & 446 & 256 & 242 & 2003 \\
\hline 92 & 57 & 56 & 2867 & 2881 & 2629 & 1654 & 303 & 421 & 278 & 236 & 2004 \\
\hline 93 & 71 & 59 & 2006 & 2979 & 1866 & 2114 & 301 & 451 & 280 & 264 & 2005 \\
\hline 91 & 80 & 59 & 2651 & 2851 & 2406 & 2267 & 339 & 465 & 307 & 275 & 2006 \\
\hline 90 & 63 & 79 & 1322 & 3151 & 1192 & 1984 & 365 & 474 & 329 & 376 & 2007 \\
\hline 96 & 52 & 80 & 1994 & 4803 & 1908 & 2490 & 652 & 491 & 623 & 394 & 2008 \\
\hline 98 & 68 & 82 & 5768 & 3149 & 5666 & 2143 & 748 & 481 & 734 & 394 & 2009 \\
\hline 100 & 100 & 100 & 2514 & 4195 & 2514 & 4195 & 630 & 484 & 630 & 484 & 2010 \\
\hline 103 & 75 & 110 & 4179 & 3976 & 4318 & 2988 & 414 & 462 & 428 & 506 & 2011 \\
\hline 100 & 83 & 113 & 2832 & 3896 & 2835 & 3221 & 671 & 443 & 671 & 499 & 2012 \\
\hline 103 & 109 & 115 & 3147 & 3220 & 3228 & 3512 & 579 & 390 & 594 & 449 & 2013 \\
\hline 102 & 83 & 116 & 3390 & 3344 & 3460 & 2766 & 383 & 379 & 391 & 439 & 2014 \\
\hline 104 & 99 & 116 & 2195 & 2734 & 2273 & 2698 & 544 & 348 & 563 & 405 & 2015 \\
\hline 95 & 192 & 124 & 2624 & 867 & 2496 & 1662 & 503 & 266 & 478 & 328 & 2016 \\
\hline & & & 2695 & 3376 & 2651 & 2361 & 436 & 470 & 428 & 351 & المتوسط \\
\hline & & & 5768 & 4803 & 5666 & 4195 & 748 & 751 & 734 & 506 & الحد الاعلى \\
\hline & & & 1322 & 867 & 1192 & 1519 & 193 & 266 & 204 & 213 & الحد الادنـي \\
\hline
\end{tabular}

المصدر: جمعت وحسبت من قواعد البيانات الزراعية لمنظمة الأغذية والزراعة للأمم المتحة (الفاو) على الثبكة الدولية للمطومات

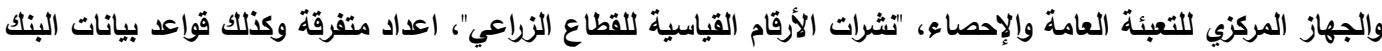

الاولي.

"باستذام الرقم القياسي للأسعار المقبوضة بواسطة الزراع بأسعار 2010، **باستخدام الرقم القياسي للصادرات بالدولار بأسعار أساس 2010. 1- السعر المحلى النقدى للأرز الأبيض= السعر المحلى للأرز الثعير x الكمية المعادلة للأرز الأبيض من الأرز الثعير، حيث ان الكمية المعادلة للأرز الأبيض = 2- السعر المحلى للقطن الثعر= السعر المحلى للقطن الزهر x الكمية المعادلة للقطن الثعر من القطن الزهر ، حيث أن الكمية

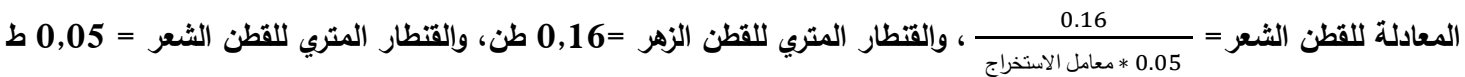


شكل (3): تطور الأسعار المحلية وأسعار تصدير محصول الأرز الأبيض بالقيم النقية والحقيقية بأسعار 2010 خلال الفترة (2000-2016) بالدولار/طن.
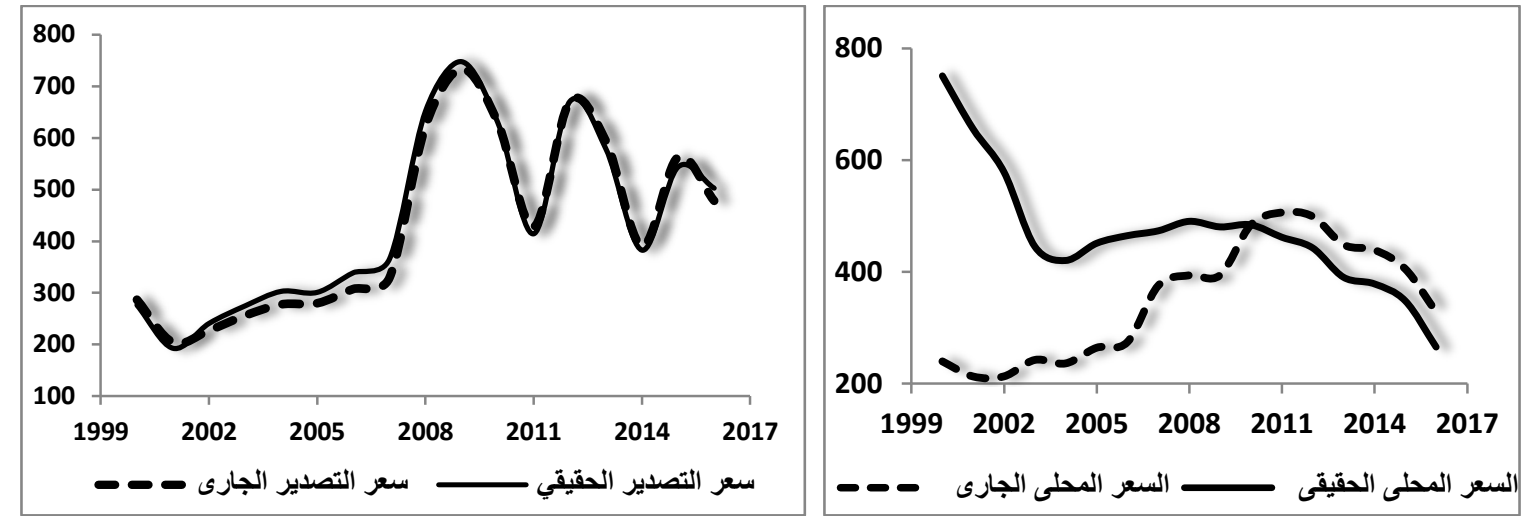

المصدر : بيانات جدول رقم (5).

أن كل من السعر المحلى النقدى والحقيقي أخذا في

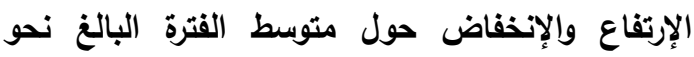

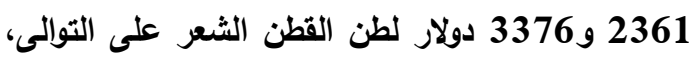
وقد مثل الحد الأقصى لسعر تصدير طن القطن الشعر النقدى والحقيقي نحو 5666 و5768 دولار عام 2009، كما بلغ الحد الأدنى لكل منهم حوالى 1192

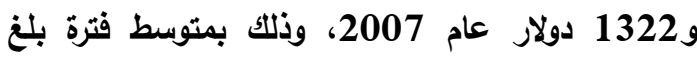
حوالى 2651 و2695 دولار لكل منهم على التوالى. ويدراسة الاتجاه الزمنى العام للسعر المحلى النقى والحقيقي لمحصول القطن خلال فترة الاراسة، تبين أن الثكل التكعيبي هو أوفق الأثكال للتعبير عن تلك فئل العلاقة وذلك عند مستوى معنوية 1\%، وعلى النحو التكائ التكال الذى تعكسه بيانات الجدول (4)، في حين لم تثبت المعنوية الإحصائية لتقيرات كلا من سعر التصدير النقلى والحقيقى مما يعنى تقلبهما حول متوسط الفترة البالغ نحو 2651 و2695 دولار لكل منهم على التوالى. ويتقلير معدل نمو السعر المحلى النقىى والحقيقي للقطن الثعر خلال فترة الاراسة، تبين ان كل منهما يزيد

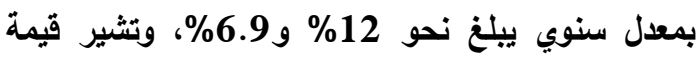

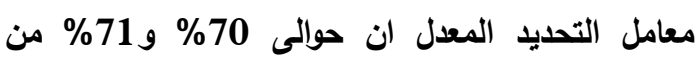
التغيرات في قيمة كل منهما على التوالى ترجع إلى العوامل الاقتصادية والتكنولوجية المرتبطة بالزمن.
ويدراسة الاتجاه الزمنى العام لكل من السعر المحلى وسعر التصدير النقدى والحقيقى لطن محصول الأرز الأبيض خلال فترة الاراسة، تبين أن النموذج التكعيبى هو الأفضل لتقديرات كل من السعر المحلى النقىى والحقيقى وسعر التصدير النقى لطن محصول الأرز

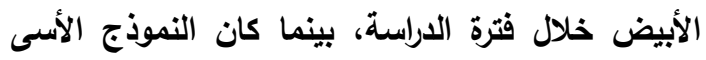
الأنسب لتقديرات سعر التصدير الحقيقيى وذلك عند مستوى معنوية 1\%، على النحو الذى تعكسه معادلات جدول رقم (4). وتثير بيانات الجدول أن السعر المصدر لطن الأزز الأبيض بالقيم الحقيقية بأسعار 2010 يزيد بمعدل

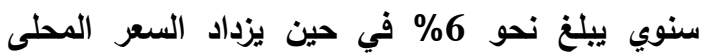
بمعدل سنوي يمثل نحو 1,8\% فقط، ويوضح معامل التحديد لكل من السعر المحلى والمصدر لمحصول الأرز الأبيض ان حوالى 92\%، 56\% من التغيرات في قيمة كل منهما على التوالي ترجع إلى العوامل الاقتصادية والتكنولوجية المرتبطة بالزمن.

$$
\text { د- القطن الشعر: }
$$

تعكس بيانات الجدول رقم (3) والثكل (4) التطور الحادث في الأسعار المحلية وأسعار تصدير محصول القطن الثعر بالدولار ويالقيم النقدية والحقيقية بأسعار 2010 خلال فترة الاراسة (2000-2016)، وقد تبين 
R. M. A. Zein, et al.,

جلول (4): تطور السعر المحلى وسعر تصدير محصولى الأرز الأبيض والقطن الثعر النقدي والحقيقي بأسعار عام 2010 خلال الفترة (2000-2016) بالدولار/ طن.

\begin{tabular}{|c|c|c|c|c|}
\hline \multicolumn{2}{|r|}{ القطن الشعر } & \multicolumn{2}{|r|}{ الأرز الأبيض } & \multirow[t]{2}{*}{ البنذ } \\
\hline المندل النمو & معادلة الاتجاه الزمني & السنوى النمو & معادلة الاتجاه الزمني & \\
\hline 12 & 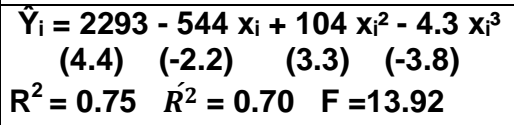 & 11 & $\begin{aligned} & \hat{Y}_{i}=292-61 x_{i}+13 x_{i}{ }^{2}-0.5 x_{i}{ }^{3} \\
&(10.8)(-4.8) \quad(8) \quad(-9) \\
& R^{2}=0.96 \quad R^{2}=0.95 \quad F=117.84\end{aligned}$ & النقاى السعى \\
\hline & لم تلثبت المعنوية & 12 & $\begin{array}{c}\hat{\mathrm{Y}}_{\mathrm{i}}=297-62 \mathrm{X}_{\mathrm{i}}+15 \mathrm{X}_{\mathrm{i}}{ }^{2}-0.6 \mathrm{X}_{\mathrm{i}}{ }^{3} \\
(2.2) \quad(-0.9) \quad(1.9) \quad(-2.2) \\
R^{2}=0.68 \quad R^{2}=0.61 \quad \mathrm{~F}=9.42\end{array}$ & سعر التصدير \\
\hline 6,9 & $\begin{array}{c}\hat{\mathrm{Y}}_{\mathrm{i}}=5945-1337 \mathrm{x}_{\mathrm{i}}+185 \mathrm{x}_{\mathrm{i}}{ }^{2}-7.2 \mathrm{x}_{\mathrm{i}}{ }^{3} \\
(9.7)(-4.7) \quad(5.1) \quad(-5.4) \\
\mathrm{R} 2=0.76 \quad \mathbf{R}^{2}=0.71 \quad F=13.99\end{array}$ & 1,8 & $\begin{array}{l}\hat{Y}_{i}=879-153 \mathrm{X}_{\mathrm{i}}+17 \mathrm{X}_{\mathrm{i}}{ }^{2}-0.6 \mathrm{X}_{\mathrm{i}}^{3} \\
(22.7) \quad(-8.5) \quad(7.5) \quad(-7.4) \\
R^{2}=0.94 \quad R^{2}=0.92 \quad F=63.53\end{array}$ & الحقيقى الحعر \\
\hline & لم تمثبت المعنوية & 6 & $\begin{array}{c}\operatorname{Ln} \hat{Y}_{\mathrm{i}}=234.6+0.06 \mathrm{x}_{\mathrm{i}} \\
(7.1)(4.4) \\
\mathrm{R}=0.75 \quad \mathrm{R}^{2}=0.56 \quad \mathrm{~F}=19.24\end{array}$ & سعر التصدير \\
\hline
\end{tabular}

المصدر: جمت وحسبت من بيانات جدول رقم (3).

شكل (4): تطور الأسعار المحلية وأسعار تصدير محصول القطن الثعر بالقيم النقدية والحقيقية بأسعار 2010 خلال

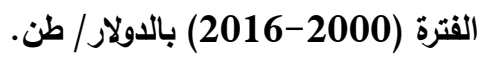

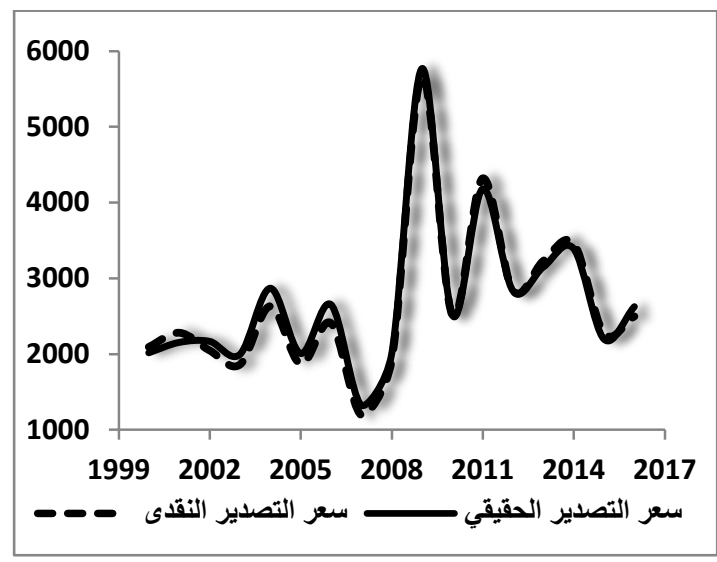

وقد تبين أن متوسط السعر المحلى النقدى والحقيقي أعلى من متوسط سعرى الاستيراد النقاى والحقيقى خلال

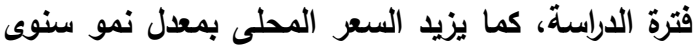

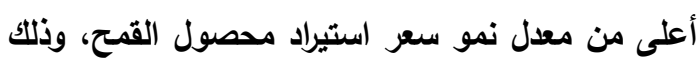
على النحو الموضح بالثكل رقم (5)، مما يعكس محاولة مدئة

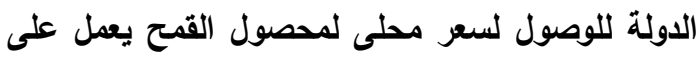

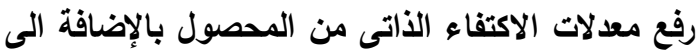
تحسين مستوى معيشة الزراع.

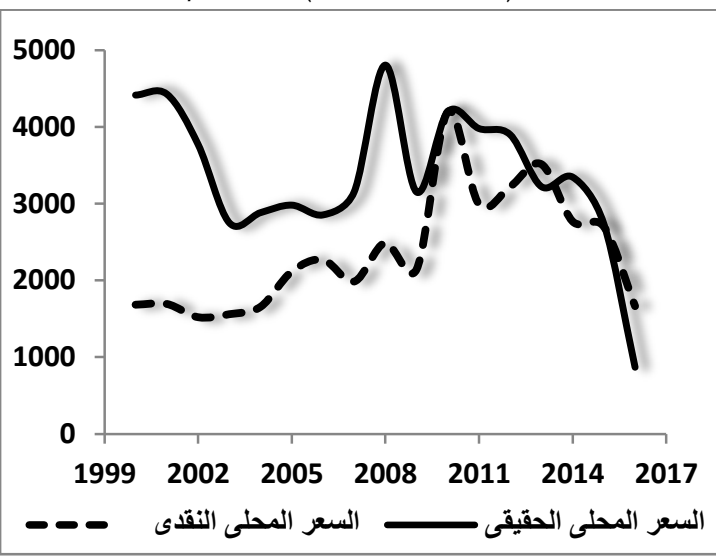

المصدر: بيانات جدول رقم (3).

ثالثاً: مقارنة الأسعار المحلية والعالمية للمحاصيل موضع الاراسة: القمح: بالرغم من اتجاه كل من السعر المحلى وسعر الاستيراد النقدى لمحصول القمح في نفس الإتجاه خلال

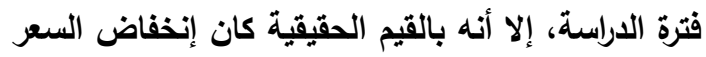
المحلى الحقيقى من بداية فترة الدراسة حتى وصل لأقل قيمه له في نهاية الفترة، بعكس سعر الاستيراد الحقيقي، لهني 
شكل(5): تطور الأسعار المحلية وأسعار استيراد طن محصول القمح بالقيم النقدية والحقيقية بأسعار 2010 خلال الفترة (2016-2000) بالدولار/ طن. (200)

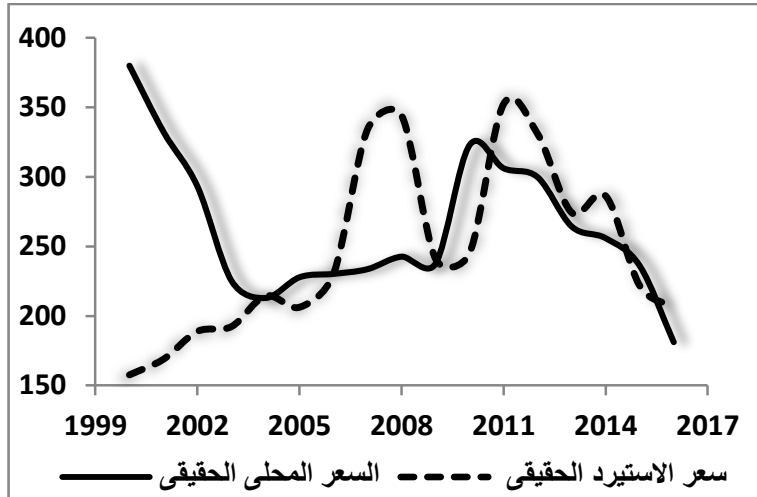

الارتفاع حتى حده الاقصى عام 2011 ثم أخذ فى الانخفاض بعد ذلك، بينما أخذ السعر المحلى الحقيقى فى الأى الانخفاض خلال نفس الفترة، وعلى الرغم من ارتفاع متوسط سعر تصدير طن الأرز الأبيض النقىى عن متوسط السعر المحلى النقدى، إلا ان متوسط السعر الانيطر المحلى الحقيقى يزيد عن متوسط سعر التصدير الحقيقى بنحو 34 دولار للطن خلال فترة الدراسة، فى حين يزيد

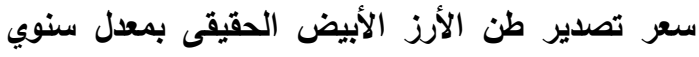

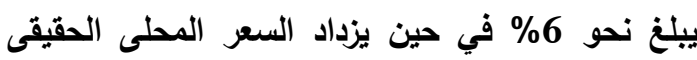
بمعل نحو 1,8\% فقط على النحو المبين بالثكل (7).

$$
\text { د- القطن الشعر: }
$$

تتقلب أسعار القطن الثعر النقية والحقيقية بأسعار 2010 بالارتفاع والانخفاض حول متوسط فترة الاراسة (2016-2000) على النحو المبين بالثكل (8)، وقات تبين أن سعر التصدير النقدى يزيد عن السعر المحلى

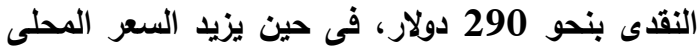
الحقيقى بأسعار 2010 عن سعر التصدير الحقيقى

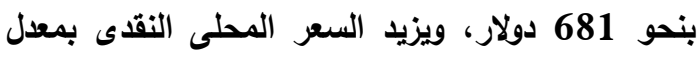
نمو سنوى ضعف معدل نمو السعر المحلى الحقيقى تقريبا، فى حيث لم تثبت معنوية أسعار تصديره.

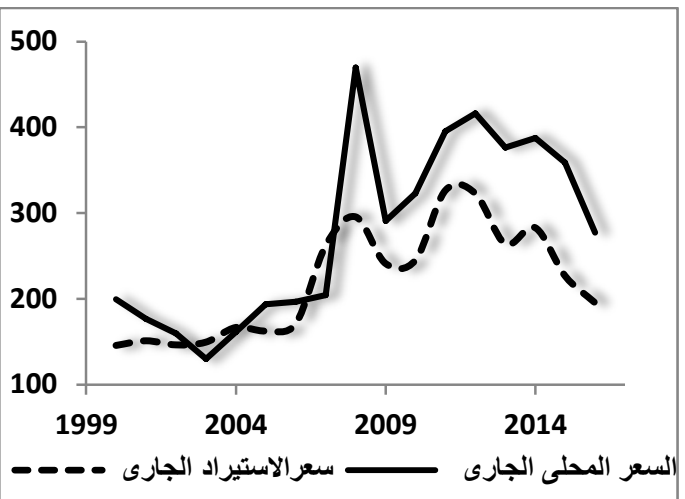

المصدر : بيانات جدول رقم (1).

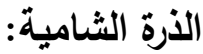

اتجهت أسعار محصول الأرة الثامية النقدية اتجاه

المحلية والاستيرادية فى الارتفاع حتى بلغت حهما الأقصى ثم أخذ كل منهما فى الانخفاض بعد ذلك، فى حين أخذ السعر المحلى الحقيقى فى الانخفاض من حد

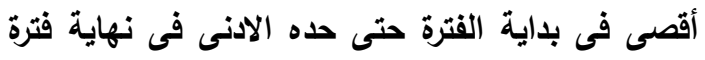
الاراسة، بينما أخذ سعر الاستيراد الحقيقى فى الارتفاع والانخفاض حول متوسط الفترة، وعلى الرغم من ارتفاع السعر المحلى النقدى والحقيقى عن متوسط سعر الإن الاستيراد النقدى والحقيقى خلال فترة الاراسة، إلا أن

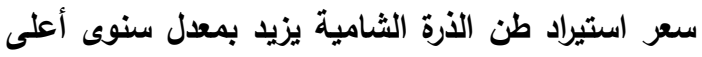
من معدل نمو سعره المطلى، حيث يزيد سعر الاستيراد الحقيقى بنحو 8 أضعاف نمو السعر المحلى تقريباً خلال تلك الفترة، وهو الأمر الأى يشير إلى وجود فجوة نسبية بين سعر المحلى وسعر استيراد طن محصول الذرة الثامية على النحو المبين بالثكل (6).

$$
\text { ج- الأرز الأبيض: }
$$

يأخذ كلا من سعر تصدير طن محصول الأرز الأبيض النقدى والحقيقى بأسعار 2010 نفس الاتجاه

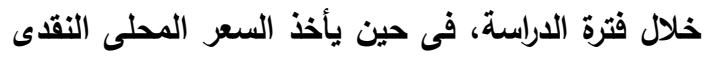


R. M. A. Zein, et al.,

شكل (6): تطور الأسعار المحلية وأسعار استيراد طن محصول الأرة الثامية بالقيم النقدية والحقيقية بأسعار 2010 خلال

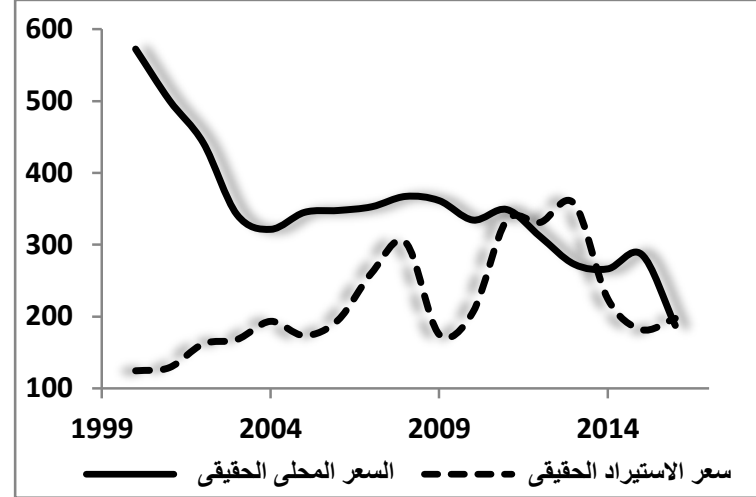

الفترة (2000-2016) بالدولار/طن.

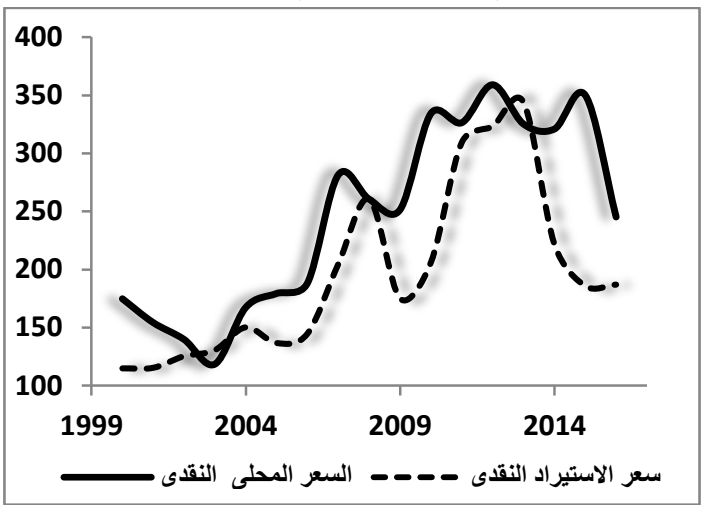

المصدر: بيانات جدول رقم (1).

شكل (7): تطور الأسعار المحلية وأسعار تصدير محصول الأرز الأبيض بالقيم النقية والحقيقية بأسعار 2010 خلال
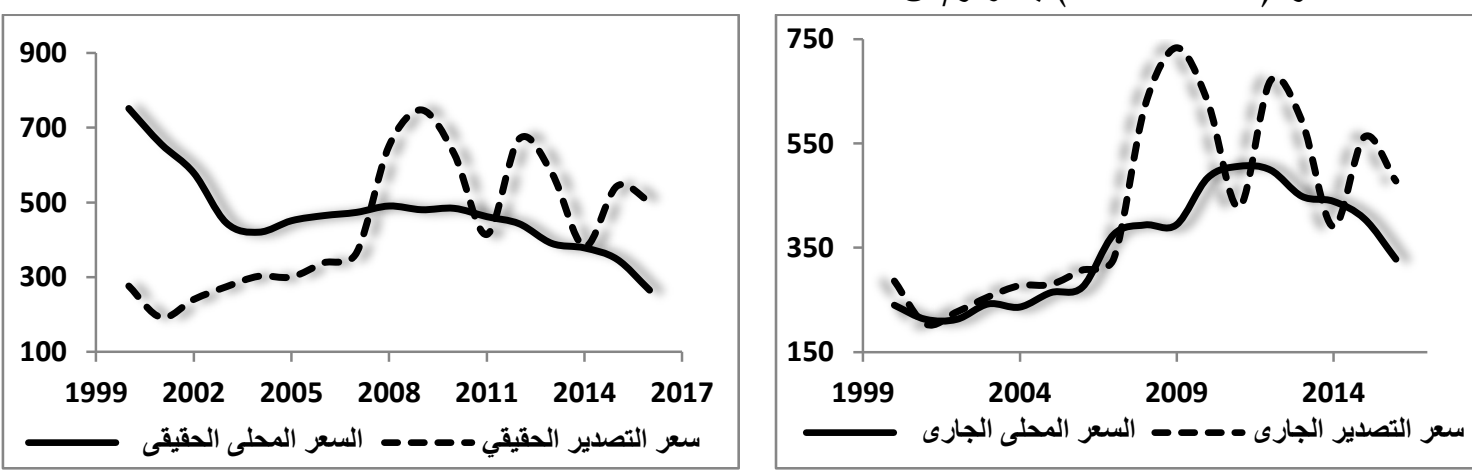

المصدر: بيانات جدول رقم (3).

شكل (8): تطور الأسعار المحلية وأسعار تصدير محصول القطن الثعر بالقيم النقدية والحقيقية بأسعار 2010 خلال الفترة (2000-2016) بالدولار/ طن.
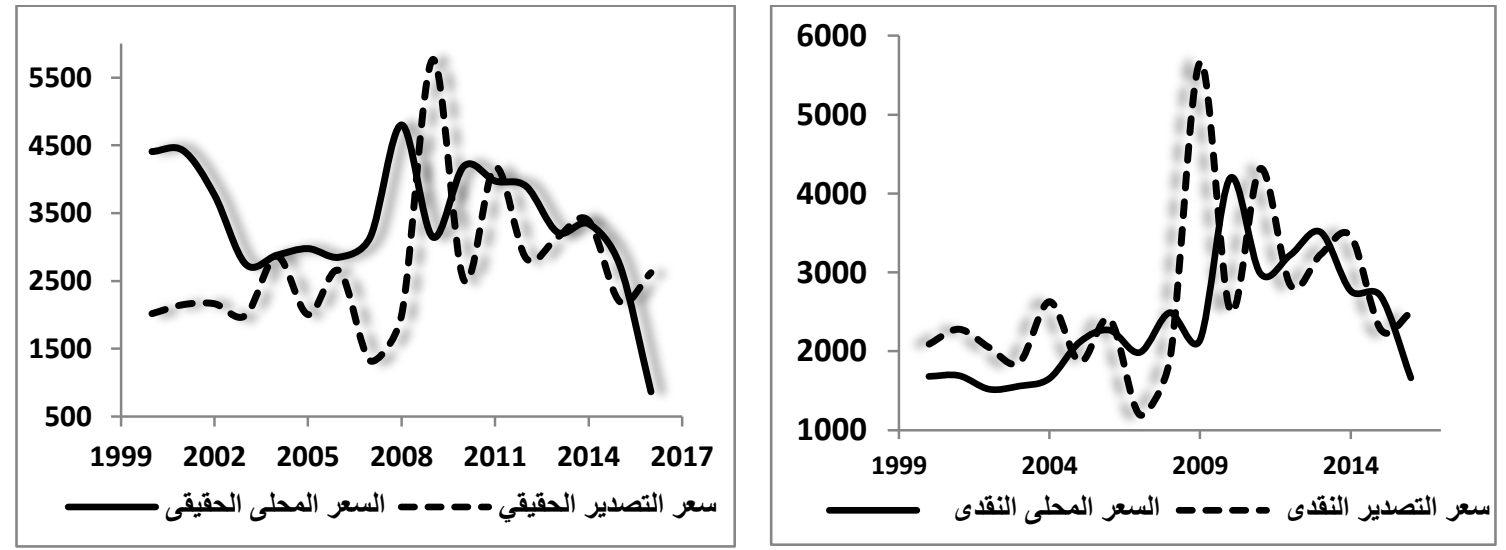

المصدر: بيانات جدول رقم (3). 
الحقيقى يزيل بمعدل سنوي يبلغ نحو 6\% في حين

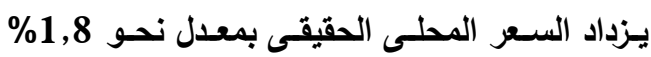

فقط.

4- تقلب أسعار القطن الثـعر النقايـة والحقيقية بأسعار سنة 2010 بالارتفاع والانخفاض حول متوسط فترة الاراسة، وكان سعر تصديره النقدى يزيد عن السعر

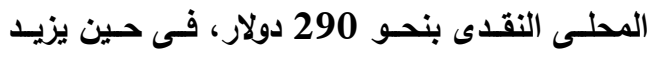
السعر المحلى الحقيقى عن سعر التصدير الحقيقى لنقي بنحو 681 دولار. وعليـه توصسى الاراسـة واضـعى السياسـات السـعرية

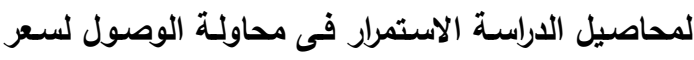
أفضل لمحصول القمح يعمل على زيادة معدلات الاكتفاء الأتى من المحصول فضلاً عن تحسين مستوى معيشـة

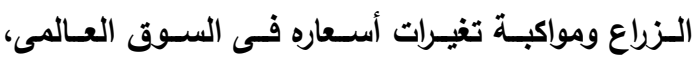
وضرورة تحسين أسعار محاصيل الذرة الثـامية والأرز الأبيض والقطن الثـعر والعمل على ضمان حدود دنيا

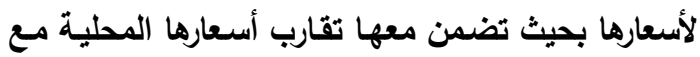
الأسـعارالعالمية، مسع إعـلان واضـعى السياسـة السـعرية لهذه الأسعار قبل موعد الزراعة بوقت كاف حتى يسترشد الاعدان

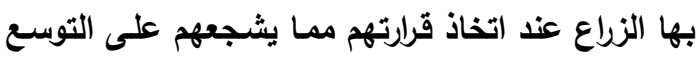
فى زراعة هذه المحاصيل.

المراجع

1- محمد، أحمد عبد الحفيظ، وعلى، عبد المجيد ابو

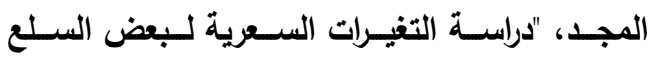

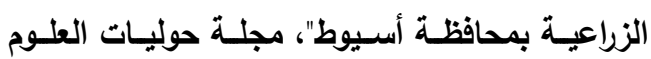

الزراعية بمشتهر، مجلا 12، عدد 1، 1979.

2- عثمان، عفاف زكى على، "دراسـة التحركات الزمنية 12

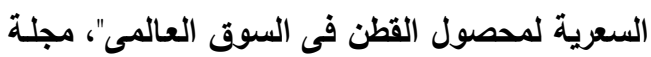

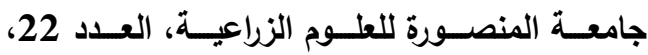

.1997

3- سـامية ريـاض عطيـة، "دراسـة اقتصـادسة للسياسـات السعرية لبعض المحاصيل الزراعية المصرية"، رسالة
أهم النتائج وإلتوصيات:

اتسمت أسعار السلع الزراعية الاستراتيجية بعدم الإستقرار، وأصبحت معظم هذه الأسعار لا تعكس القيمة

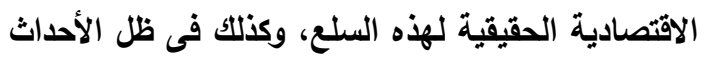

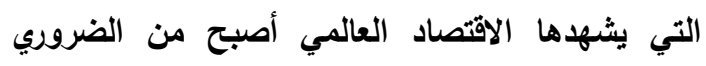
دراسة الأسعار المحلية للسلع الاستراتيجية واتجاهها ومدى انحرافها عن نظيرتها العالمية. وعليه تم دراسة وتحليل الاتجاه الزمنى العام للأسعار المحلية النقدية

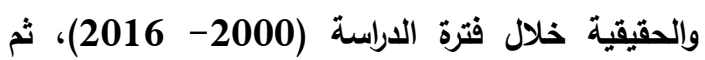
مقارنتها بالأسعار العالمية ومدى تثتتها وقربها من بعضها البعض خلال نفس الفترة للمحاصيل موضع الاراسة والتي تمثلت فى محصولى القمح والذرة الثامية كمحاصيل استيرادية ومحصولى الأرز الأبيض والقطن الثعر كمحاصيل تصديرية هامة، وكانت من أهم النتائج: 1- متوسط السعر المحلى النقدى والحقيقي لمحصول

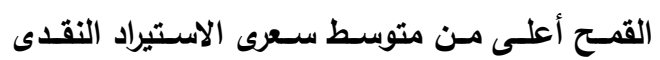

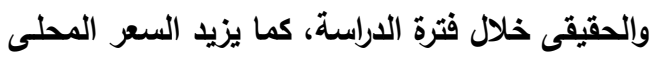

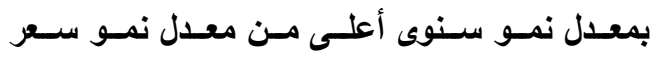

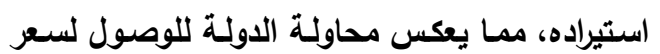

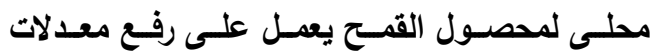
الاكتفاء الذاتى من ناحية، وتحسين مستوى الزراع من ناحية أخرى.

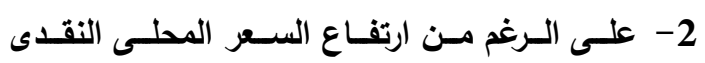

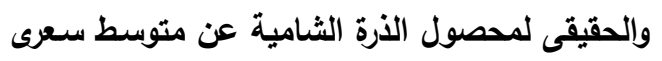
الاستيراد النقدى والحقيقى خلال نفس الفترة، إلا أن سعر استيراد طن الأرة الثامية يزيد بمعدل نمو يعادل

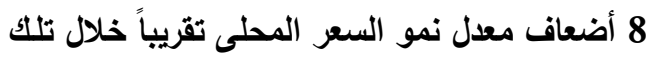
الفترة. 3- ارتفـاع متوسـطس سعر تصـدير طن الأرز الأبسيض

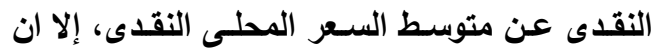

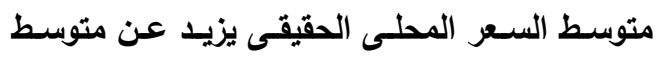
سعر التصدير الحقيقى بنحو 34 دولار للطن خلال

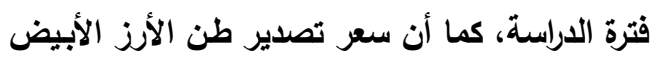


7- عثمان، بليغ حمدى والثويخ، داليا حامد وإسماعيل، عثمان على ومحمد، أحمد عبد الحفيظ، "أثر الأزمات

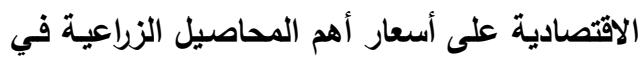
مصر"، مجلة العلوم الزراعية بأسيوط، مجلد 48،

$$
\text { العدد (1-2)، } 2017 .
$$

8- "إحصـاءات التجــارة الخارجيـة للصــادرات والــواردات

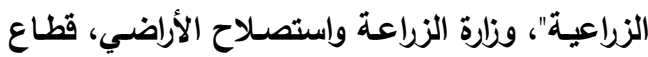
الثئون الاقتصادية، أعداد متفرقة. 9- "تثـرات الإحصـاءات الزراعيـة المحاصيل الصـيفية

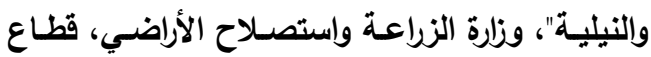
الشئون الاقتصادية، أعداد متفرقة.

10- https://www.albankaldawli.org/. 11-http://www.fao.org/giews/pricetool/
دكتـوراه، قسـم الاقتصــاد الزراعسى، كليـة الزراعـة، جامعة عين شمس، 2002. 4- الكاشف، منس فؤاد محمد اسماعيل، "أثر الأسعار

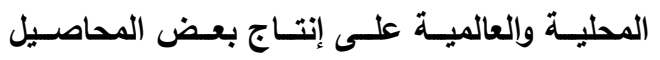
الرئيسية فى مصر"، رسالة ماجستير، قسم الاقتصاد

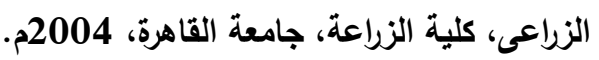

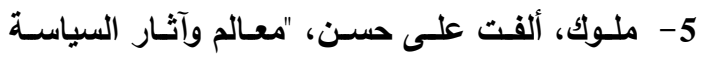
السعرية والتسويقية لمحاصيل الحبوب"، مجلة العوم الزراعية والبيئية، جامعة الإسكندرية، مجلد 6، عدد .2007، 3

6- الثـيخ، ناديـة حسين وآخرون، "تحليـل اقتصـادى

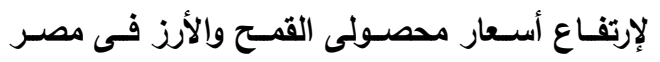

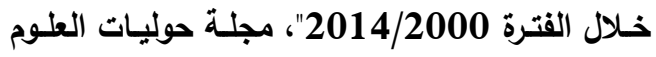
الزراعيـة بمشــهر ، كليـة الزراعـة، جامعـة بنهـا، المجلا 55، العدد 1، مارس 2017. 


\title{
AN ANALYTICAL STUDY OF THE GROWTH IN DOMESTIC AND INTERNATIONAL PRICES OF THE MOST IMPORTANT CROPS IN THE EGYPTIAN AGRICULTURAL FOREIGN TRADE
}

\author{
R. M. A. Zein, Yousra E. A. Shakra and Eman E. K. M. El Bahgy \\ Dept. of Agricultural Economics and Agri-business Faculty of Agriculture \\ Menoufia University
}

\begin{abstract}
Prices and price policies are very important due to their role in guiding resources between different types of production and distribution of production among consumers, as well as their impact on the economic efficiency of resource use, the fairness of distribution of incomes and their impact on consumption, the volume of net revenue from agricultural foreign trade, and finally its impact on the standard of living for farmers and consumers alike.
\end{abstract}

However, such policies face many difficulties due to their interrelated economic, social and technological aspects, where the prices of strategic agricultural commodities have been characterized by instability, and most of these prices do not reflect the real economic value of the commodities, In the light of events in the world economy, it is necessary to examine the domestic prices of strategic goods, their direction and extent of thier deviation from their global counterparts.

The problem of the study was the fairness of local prices for strategic agricultural crops gained by farmers and the extent to which they keep pace with the changes in export and import prices, and thus their impact on agricultural incomes and the standard of living of the growers producing these crops. In order to achieve the goal of the research, the historical review of the agricultural price policies of the crops studied in Egypt, and the study of the general temporal trend of local and international monetary and real prices during the study period (2000-2016), and then compared prices for the crops of the study, Dispersed and close to each other during the same period, and access to recommendations that will benefit agricultural policy makers in formulating a policy for the pricing of studied agricultural crops.

The studied crops were selected according to their relative importance in Egyptian agricultural foreign trade during the period 2012-2016. Rice and cotton were the highest export grain and fiber crops, and wheat and maize were the highest import grain crops. The research was based on descriptive and quantitative economic analysis methods, as well as on secondary data issued by various stakeholders, By examining the current situation of local and global cash and real prices in terms for the year 2000, it was found that the average local cash and real price of wheat crop is higher than the average prices of the cash and real import prices during the study period, and the local price increases at a higher annual growth rate than the import price, referes to the state's attempt to reach a local price for wheat crop, which raises the rates of self-sufficiency on the one hand, and improves the level of farmers on the other.

Although the local monetary and real price of the maize crop increased from the average prices of the import of cash and real during the same period, the real import price is increasing at an annual rate of about eight times the growth of the domestic price during this period, The average export price of a ton of white rice is higher than it's average domestic cash price, and the export price of a tonne of real white rice increases at an annual rate of about $6 \%$, while the real domestic price increases by only about $1.8 \%$. Cotton prices fluctuate with cash and real 2010 prices, rising and falling around the 
An analytical study of the growth in domestic and international prices of ............

average study period of about $\$ 2,361$ and $\$ 3,376$ for the domestic price and about $\$ 2,651$ and \$2,695 for the export price, respectively. It has been shown that the cash export price is more than the domestic price by about $\$ 290$, while the real domestic price is about $\$ 681$ more than the real export price, and the domestic price increases at an annual growth rate twice the rate of growth of the real domestic price.

According to the results, the study recommends that the policy makers of the study crops continue to try to reach a better price for wheat crop works to increase the rates of self-sufficiency of the crop as well as improve the standard of living of farmers and keep up with the changes in its prices in the world market, and the need to improve the prices of maize crops, white rice and cotton lint and work to ensure minimum prices so that it guarantees the convergence of local prices with world prices, with the announcement of the price of these crops well in advance of the date of agriculture to guide the farmers when making their decisions, which encourages them to expand in These agriculture crops.

Key words: Domestic and International prices, price policies, strategic agricultural Crops, monetary and real prices. 
